\title{
Cell Adhesion Molecules and Their Involvement in Autism Spectrum Disorder
}

\author{
Haihong $\mathrm{Ye}^{\mathrm{a}}$ Jianghong Liu ${ }^{\mathrm{a}}$ Jane Y. Wu \\ aThe State Key Laboratory of Brain and Cognitive Science, Institute of Biophysics, Chinese Academy of Sciences, \\ Beijing, China; ${ }^{b}$ Department of Neurology, Center for Genetic Medicine, Lurie Cancer Center, Northwestern \\ University Feinberg School of Medicine, Chicago, III., USA
}

\section{Key Words}

Autism spectrum disorder - Cell adhesion molecules •

Neural development $\cdot$ Neurexins

\begin{abstract}
Autism spectrum disorder (ASD) is a group of neurodevelopmental disorders characterized by abnormalities in social interaction, language development and behavior. Recent genetic studies demonstrate that alterations in synaptic genes including those encoding cell adhesion molecules and their interaction partners play important roles in the pathogenesis of ASD. Systematic analyses of different cell adhesion molecule genes will help elucidate their normal functions and regulatory mechanisms in the establishment and maintenance of normal neural circuits and uncover genetic aberrations contributing to ASD.

Copyright $\odot 2011$ S. Karger AG, Base
\end{abstract}

\section{Introduction}

Autism is a group of neurodevelopmental disorders affecting many aspects of cognition and behavior. Children with autism exhibit impaired language development, social interaction deficits and repetitive behavior. Autism is a highly variable syndrome with significantly different severity. Thus, the term autism spectrum disorder (ASD) is used to encompass a range of disorders with such impairment in language development, social interaction and behavior [1]. Genetic research on ASD indicates a significant genetic contribution to its etiology. The concordance rate of ASD for monozygotic twins is $70-90 \%$, but less than $10 \%$ for dizygotic twins. Children with autistic siblings are 25-fold more likely to develop ASD than those without [2]. In contrast to many other brain disorders, for example, Parkinson disease or Alzheimer's disease, the etiology underlying ASD at the molecular, cellular and system level remains elusive. ASD genetics is highly complex, involving many genes and different genetic variations, such as deletion, translocation, single nucleotide polymorphism (SNP) and copy number variation (CNV) [2-4]. The therapeutic tools for ASD treatment are extremely limited.

Symptoms and signs of ASD often appear in the first 3 years of life, during which the learning ability is rapidly developing. This period correlates with a phase of intensive synaptogenesis, a relatively late step in the brain development [5]. Many genes associated with ASD play important roles in synaptic formation and activity [6]. Thus, ASD is often referred to as a synaptic disease. Neuronal synapses are intercellular junctional structures spe-

\section{KARGER}

Fax +4161306 1234 E-Mail karger@karger.ch www.karger.com

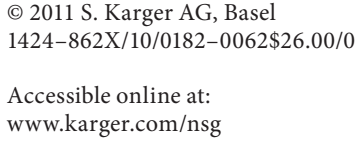

Dr. Jane Y. Wu

Department of Neurology and Center for Genetic Medicine, Northwestern University Feinberg School of Medicine, Robert H. Lurie Comprehensive Cancer Center 303 E. Superior St., Lurie Building, Rm 7117, Chicago, IL 60611 (USA)

Tel. +1 312503 0682, Fax +1 312503 5603, E-Mail jane-wu@ northwestern.edu 
Table 1. ASD susceptibility genes encoding human CAMs and CAM-related genes

\begin{tabular}{|c|c|c|}
\hline Gene symbol & Full name & Chromosomal location \\
\hline \multicolumn{3}{|l|}{ Neurexin family } \\
\hline NRXN1* & Neurexin 1 & $2 \mathrm{p} 16.3$ \\
\hline CNTNAP2* & Contactin associated protein-like 2 & $7 \mathrm{q} 35-\mathrm{q} 36$ \\
\hline CNTNAP5 & Contactin-associated protein-like 5 & $2 \mathrm{q} 14.3$ \\
\hline \multicolumn{3}{|c|}{ Neuroligin family } \\
\hline NLGN1 & Neuroligin 1 & $3 q 26.31$ \\
\hline NLGN3* & Neuroligin 3 & Xp22.32-p22.31 \\
\hline NLGN4X* & Neuroligin 4, X-linked & Xq13.1 \\
\hline NLGN4Y & Neuroligin 4, Y-linked & Yq11.221 \\
\hline \multicolumn{3}{|l|}{ Ig family } \\
\hline CNTN3 & Contactin 3 & $3 \mathrm{p} 26$ \\
\hline CNTN4 & Contactin 4 & $3 \mathrm{p} 26-\mathrm{p} 25$ \\
\hline NRCAM & Neuronal cell adhesion molecule & $7 \mathrm{q} 31.1-\mathrm{q} 31.2$ \\
\hline CADM1 & Cell adhesion molecule 1 & $11 \mathrm{q} 23.2$ \\
\hline ROBO1 & Roundabout, axon guidance receptor, homolog 1 & $3 \mathrm{p} 12$ \\
\hline $\mathrm{ROBO} 2$ & Roundabout, axon guidance receptor, homolog 2 & $3 \mathrm{p} 12.3$ \\
\hline ROBO3 & Roundabout, axon guidance receptor, homolog 3 & $11 \mathrm{q} 24.2$ \\
\hline ROBO4 & Roundabout homolog 4, magic roundabout & $11 \mathrm{q} 24.2$ \\
\hline \multicolumn{3}{|l|}{ Cadherin family } \\
\hline $\mathrm{CDH} 9$ & Cadherin 9 & $5 \mathrm{p} 14.1$ \\
\hline $\mathrm{CDH} 10$ & Cadherin 10 & $5 \mathrm{p} 14.2$ \\
\hline $\mathrm{CDH} 18$ & Cadherin 18 & $5 \mathrm{p} 14.3$ \\
\hline PCDH9 & Protocadherin 9 & $13 \mathrm{q} 21.32$ \\
\hline PCDH10 & Protocadherin 10 & $4 q 28.3$ \\
\hline \multicolumn{3}{|l|}{ Integrins } \\
\hline ITGB3* & Integrin, $\beta_{3}$ & $17 \mathrm{q} 21.32$ \\
\hline ITGA4 & Integrin, $\alpha_{4}$ & $2 \mathrm{q} 31.3$ \\
\hline \multicolumn{3}{|l|}{ Other CAMs } \\
\hline ASTN2 & Astrotactin 2 & $9 q 33.1$ \\
\hline \multicolumn{3}{|c|}{ Genes involved in CAM signaling pathways } \\
\hline SHANK1 & SH3 and multiple ankyrin repeat domains 1 & $19 q 13.3$ \\
\hline SHANK2 & SH3 and multiple ankyrin repeat domains 2 & $11 \mathrm{q} 13.3$ \\
\hline SHANK3* & SH3 and multiple ankyrin repeat domains 3 & $22 \mathrm{q} 13.3$ \\
\hline SLC6A4* & Serotonin transporter & $17 \mathrm{q} 11.2$ \\
\hline LAMB1 & Laminin, $\beta_{1}$ & $7 q 31.1$ \\
\hline
\end{tabular}

Asterisks indicate genes that show strong association with ASD.

cialized in transmitting information between neurons or from neurons to their target nonneuronal cells. Synaptic formation and specification involves at least three steps: pathfinding and initial recognition of the target cells by the axonal growth cone, formation of the synaptic junction with assembly of synaptic complexes, and synaptic specification/maturation. Proper establishment of neural circuits and neuronal identity specification is crucial for the formation of the nervous system. It is likely that abnormality in this process may cause abnormal cognitive conditions including autism.

CAMs and Their Involvement in Autism Spectrum Disorder
Among the ASD susceptibility genes already identified in the genetic studies, a prominent group are the genes encoding cell adhesion molecules (CAMs) and genes involved in CAM signaling pathways. Out of 200 or so ASD-associated genes identified so far, at least 28 are CAMs or CAM-related genes (table 1). CAMs are cell surface glycoproteins that mediate cell-cell and cell-extracellular matrix interaction. They play important roles in neural development, especially in synaptic formation and function $[7,8]$. There are four main groups of CAMs, the integrin family, the immunoglobulin superfamily, se-

Neurosignals 2010;18:62-71 
Fig. 1. Domain structures of CAMs associated with ASD.

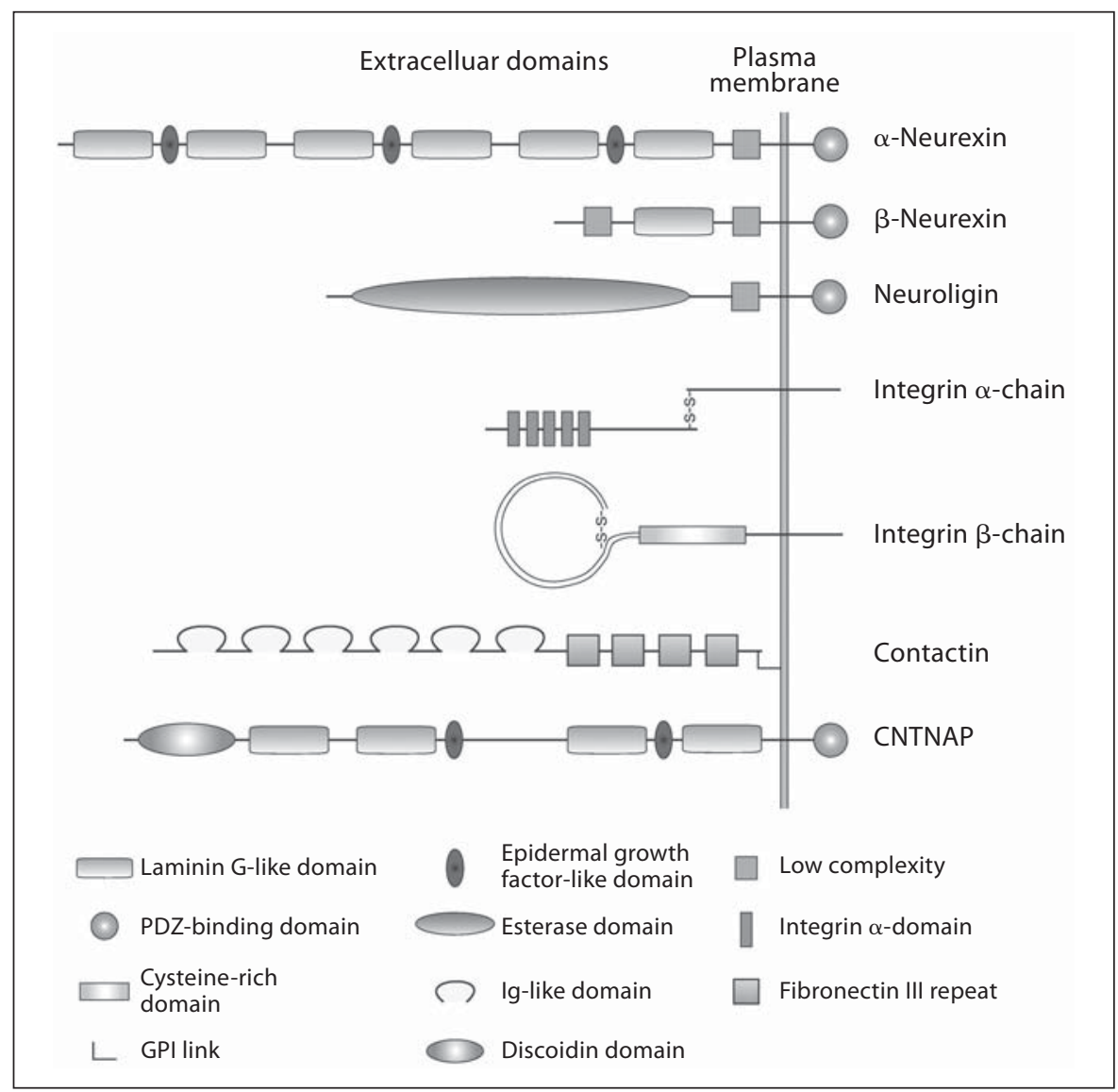

lectins and cadherins in addition to a number of other glycoproteins. Each family of CAMs has multiple members that may have overlapping function. Moreover, many genes encoding CAMs have multiple promoters and undergo extensive alternative splicing, producing multiple distinct gene products from each gene. Brain CAMs exhibit specific expression pattern in neural development, with some expressed only at a certain stage in a restricted brain area. With functional redundancy and specific expression patterns of many CAMs, mutations in these CAMs may only result in subtle changes in wiring of neural circuitry that cause specific cognitive diseases, such as ASD, but not lethality or severe defects [9].

Here, we review recent studies that associate genetic changes in CAMs with ASD. We will focus on neurexins, neuroligins, integrins, contactins and their interacting proteins, because of their strong genetic association with ASD (table 1). We will present studies about their roles in neural development and function and discuss the possible etiology of ASD as well as the future direction in the study of CAMs and ASD.

\section{Neurexins and Neuroligins}

The neurexin family are type I transmembrane proteins containing epidermal growth factor-like repeats (EGF-like) and laminin G domains in their extracellular region (fig. 1). There are three neurexins (neurexin 1-3) and five contactin-associated proteins (CNTNAP1-5) in this family. Neurexins, mainly localized at the presynaptic membrane, bind to postsynaptic neuroligins (fig. 2) and function in synaptic formation and differentiation [10-12]. The three neurexin genes, NRXN1, NRXN2, $N R X N 3$, give rise to numerous mRNA transcripts and protein isoforms via alternative splicing [13]. Moreover, each NRXN gene utilizes two alternative promoters. The majority of $N R X N$ transcripts are produced from the upstream promoter and encode $\alpha$-neurexin. A small proportion of transcripts is produced from the downstream promoter and encodes $\beta$-neurexin isoforms containing only a single laminin $\mathrm{G}$ domain (fig. 1).

Among three NRXNs, NRXN1 has been associated with ASD in several studies. The NRXN1 gene alteration 
Fig. 2. Localization of CAMs and their interacting proteins at the synapse. Proteins associated with ASD are underlined.

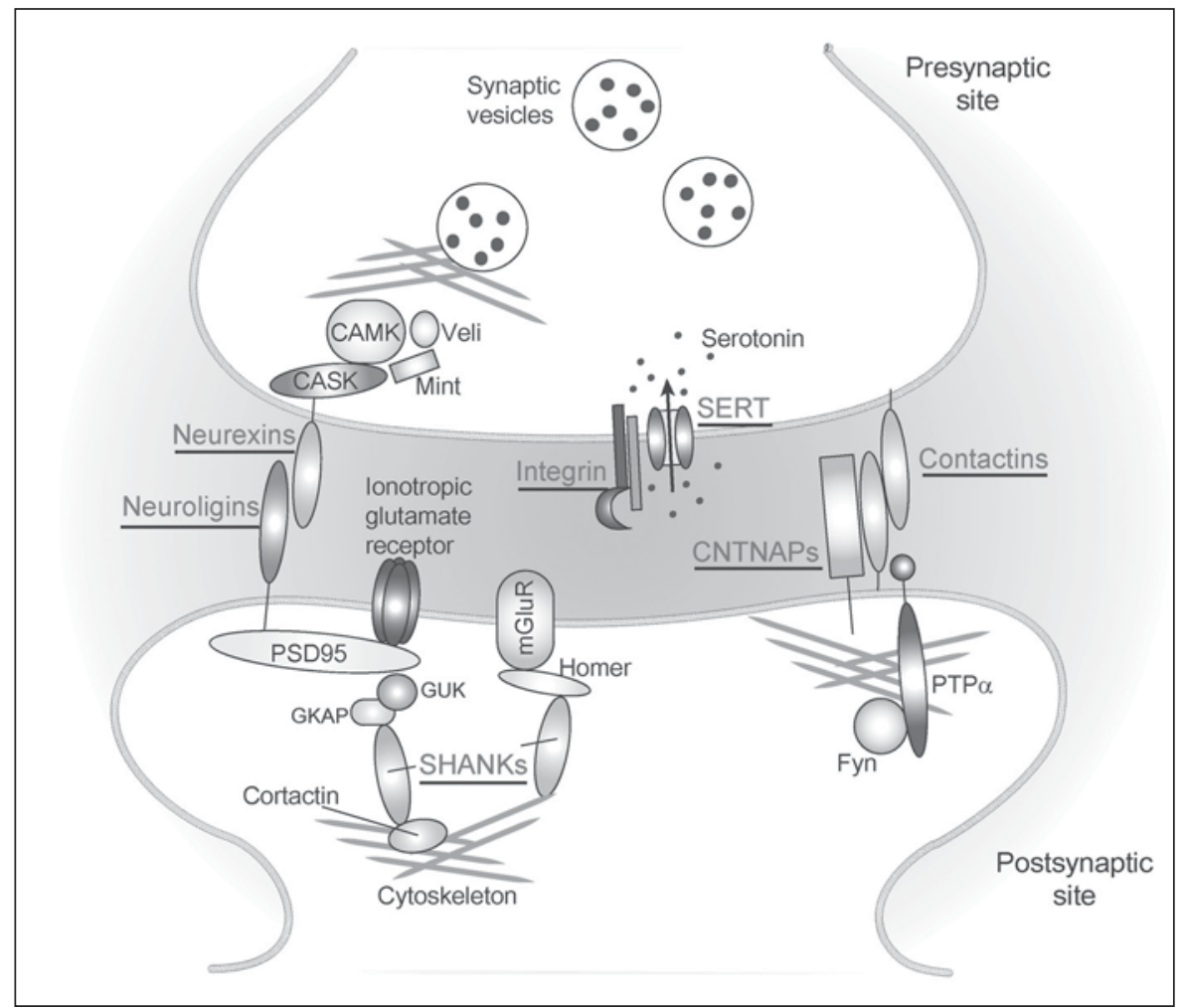

was first identified in a 7-year-old boy with Asperger syndrome $[14,15]$. Genetic analysis of this patient revealed a de novo $320-\mathrm{kb}$ deletion that removes the promoter and initial coding exons of the NRXN1 gene, resulting in deletion of neurexin $1 \alpha$ without affecting neurexin $1 \beta$. In an independent study, two missense structural variants in the neurexin $1 \beta$ signal peptide region were identified in 4 ASD patients but not in 535 healthy controls [16]. Enrichment of CNV in NRXN1 gene has also been detected in genome-wide studies of ASD patients $[3,17,18]$. Translocations and intragenic rearrangements within or near NRXN1 gene have also been identified in patients with ASD $[19,20]$.

Animal models have been developed to study the functions of neurexin 1 in synaptic formation and animal behaviors and to explore the possible mechanism of ASD pathogenesis. Overexpression of Nrx-1, an NRXN1 ortholog in Drosophila, leads to increased density of active zones [21]. Etherton et al. [22] showed that neurexin $1 \alpha-$ deficient mice exhibit deficits in excitatory synaptic strength, but not in inhibitory synaptic transmission in hippocampus. Compared with the littermate wild-type mice, neurexin $1 \alpha$-deficient mice displayed abnormal behaviors, such as a decrease in prepulse inhibition, an in- crease in grooming behaviors and an impairment in nestbuilding activity. Deficit in prepulse inhibition is a hallmark of schizophrenia. Therefore, some of the behavior changes in the neurexin $1 \alpha$-deficient mice correlate, at least in part, with impairments observed in schizophrenic patients. This is consistent with the fact that NRXN1 gene alterations have been identified in patients with schizophrenia [22-24]. However, neurexin $1 \alpha$-deficient mice do not exhibit obvious deficits in social behaviors [22]. This may be due to the lack of social behavior tests in mice that precisely recapitulate human behaviors.

Neuroligins are postsynaptic proteins that bind to $\beta$ neurexins. There are five neuroligins in the human genome, NLGN1, NLGN2, NLGN3, NLGN4X and NLGN4Y. Neuroligins share similar domain structures: an esterase domain, a single transmembrane domain followed by a short cytoplasmic domain (fig. 1). Among these five neuroligins, ASD has been associated with the X chromosome-linked NLGN3 and NLGN4X in addition to NLGN1. Jamain et al. [25] reported the first mutations in NLGN4X and NLGN3 genes in patients with autism and Asperger syndrome. In this study, an R451C mutation within the esterase domain of neuroligin 3 was identified in a Swedish family with two affected boys [25]. Various other mu- 
tations in NLGN3 and NLGN4X genes have been identified in ASD patients [26-32]. Some of these mutations were studied at the functional level to reveal their possible linkage with ASD. The R451C mutation in NLGN3 causes deficits both in neuroligin 3 trafficking from the endoplasmic reticulum (ER) to the cell surface and in its binding to neurexin [33]. An R87W substitution in NLGN4X, identified in 2 brothers with ASD, impairs its glycosylation and leads to its ER retention in neurons. As a result, the R87W mutation reduces targeting of neuroligin $4 \mathrm{X}$ to the postsynaptic membrane and abolishes its function in the synapse [34]. Another de novo single nucleotide (G335A) substitution located in the promoter region of NLGN4X gene was identified in an ASD patient, and the level of the NLGN4X transcript is increased in this patient [27]. Recently, increased CNVs in NLGN1 have been found in ASD patients as compared to control subjects [3].

$N g \ln 3$ - and $\mathrm{Ng} \ln 4$ - knockout mice have been generated. Both mutant mice display reduced social interactions and ultrasound vocalization, a behavioral phenotype reminiscent of the major symptoms of ASD [35, 36]. Neuroligin 3-deficient mice also exhibit a lack of social novelty preference, which may be due to an olfactory deficiency observed in this mutant [36]. In Ngln3 R451C knock-in mice, there is an increase in the inhibitory synaptic transmission and no apparent change in excitatory synapses. These mice exhibit impaired social interactions but enhanced spatial learning abilities [37]. Interestingly, although the association of NGLN1 with ASD is only indicated by limited human genetic studies [3], Ngln1 KO mice exhibit a dramatic increase in repetitive, stereotyped grooming behavior, another major autism-associated abnormality. This increased repetitive grooming behavior can be rescued by administration of an NMDA receptor partial co-agonist D-cycloserine, suggesting that change of glutamatergic synapses is involved in this behavior [38]. Together, these Nlgn mutant mice represent useful animal models for understanding pathological mechanism of ASD and for developing novel treatment strategies for this disease.

A scaffolding protein, SHANK3, in the NRXN-NLGN pathway has also been associated with ASD. There are three SHANK proteins, SHANK1-3. SHANKs are crucial components of the postsynaptic density that link ionotropic and metabotropic glutamate receptor complexes to the cytoskeleton [39] (fig. 2). SHANK binds to neuroligins directly or indirectly in the postsynaptic density (PSD). The human SHANK3 gene is located on chromosome 22q13, a region deleted or amplified in some
ASD patients [40-43]. Two mutations in SHANK3 gene, one at an intronic donor splice site and one missense in the coding region, have been identified in ASD patients [44]. However, two groups did not observe significant association between SNPs or CNVs in SHANK3 gene and ASD in their studies with the relatively small sample sizes (less than 350 families for each study) [45, 46]. Further studies with larger and better stratified patient samples may be necessary to confirm the association of SHANK3 with ASD.

Our knowledge of the biological function of the NRXN-NLGN-SHANK pathway in the human brain remains limited. Nonetheless, studies using cell lines, neuronal culture and transgenic mouse models have provided us substantial information about its function in the synapse. Different neuroligins and neurexins are expressed and exert their functions in different synapses for their specification and maintenance. For example, neuroligin 1 and neuroligin 3 are expressed in the glutamatergic synapses, whereas neuroligin 2 is located specifically at the GABAergic synapses [47]. Mice carrying an R451C mutation in the Nlgn3 gene exhibit an increase in the number of GABAergic synapses and the amplitude of inhibitory currents, suggesting that the R451C mutation switches the NLGN3 synaptic specificity from glutamatergic to GABAergic [37]. Neuroligins also regulate the speed of synapse formation, as thrombospondin 1 accelerates synapse formation via neuroligin 1 in cultured hippocampal neurons [48]. SHANK proteins link the postsynaptic membrane proteins to the actin cytoskeleton and regulate morphology and maturation of dendritic spines in vitro $[49,50]$.

Thus, numerous studies based on human genetic analysis, cell biology and animal models strongly suggest a linkage of the NRXN-NLGN pathway with ASD and support the important role of this pathway in synapse formation, specification and maintenance. Further study of this pathway may shed light on the etiology of ASD.

\section{Integrins and Serotonin Transporter SERT}

The integrins, composed of two noncovalently bound subunits $\alpha$ and $\beta$ (fig. 1), are dynamic and versatile CAMs. There are twelve types of $\alpha$-subunits and seven types of $\beta$-subunits, which generate numerous $\alpha-\beta$ combinations and create integrins with specific ligand-binding characteristics. Among all the integrin subunits, the $\beta_{3}$-subunit (encoded by ITGB3 gene) has recently been associated with autism. ITGB3 was first identified as a male quanti- 
tative trait locus influencing whole-blood serotonin levels in the Hutterites, a young founder population of European descent [51]. Hyperserotonemia is one of the bestreplicated neurochemical findings among more than one quarter of autistic patients $[52,53]$. In an effort to examine the possible link between ITGB3 and autism, Weiss et al. [54] identified a coding variant of ITGB3, the Leu allele at SNP 8, in a large multiplex associated with ASD. Subsequently, genetic interaction of ITGB3 and SLC6A4 (encoding serotonin transporter SERT) in hyperserotonemia and autism was discovered and confirmed by several groups [55-58]. SLC6A4 has long been recognized as an ASD susceptibility gene. The first hint of the linkage between SLC6A4 and ASD came from a genetic study in which preferential transmission of a short variant of the SLC6A4 gene promoter was discovered in 86 trios consisting of probands with ASD and both parents [59]. In addition to its association with hyperserotonemia, multiple lines of evidence support the involvement of SLC6A4 in ASD. Genome-wide screenings for autism-susceptibility loci identified chromosome 17q11-q21, a region containing SLC6A4 [60, 61]. Various SLC6A4 polymorphisms have been associated with rigid-compulsive behavior and poor nonverbal communication observed in a subset of ASD patients [62-64]. It is proposed that SLC6A4 represents a susceptibility gene for subgroups of ASD patients with hyperserotonemia and rigid-compulsive behavior [65].

How do variations in ITGB3 and SLC6A4 genes work synergistically to affect whole blood serotonin level and brain function? The work by Carneiro et al. [66] on the interaction of integrin $\alpha_{\mathrm{II}} \beta_{3}$ and SERT using platelets provided a clue. They found that integrin $\alpha_{\mathrm{IIb}} \beta_{3}$ interacts directly with the $C$ terminus of SERT. Fibrinogen, an activator of integrin $\alpha_{\mathrm{IIb}} \beta_{3}$, enhances SERT activity in human platelets. Consistently, the ITGB3 $\mathrm{Pl}^{\mathrm{A} 2}$ (Pro33) variant, a constitutively active allele of human integrin $\beta_{3}$, elevates SERT surface expression and serotonin uptake in HEK293 cells. This provides a mechanistic explanation for the genetic interaction of ITGB3 and SLC6A4 polymorphisms in hyperserotonemia. If these findings in platelets are also true in neurons, integrins may affect extracellular serotonin availability and synaptic activity by modulating serotonin uptake at the presynaptic site (fig. 2). Direct assessments of integrin-SERT interaction in neurons and synaptic serotonin levels in ASD patients are necessary to confirm this hypothesis. Nevertheless, integrin $\beta_{3}$ does represent a promising drug target that warrants further investigation. Various integrins are expressed in the developing and mature nervous system, playing important roles in neurite outgrowth and synapse formation [67, 68]. ITGA4 and LAMB1, encoding integrin subunit $\alpha_{4}$ and integrin ligand laminin $\beta_{1}$, respectively, are also ASD susceptibility genes $[69,70]$. It will not be surprising if other integrins and their signaling molecules are associated with ASD in the future studies.

\section{Contactins and Contactin-Associated Proteins}

The contactin family belongs to the immunoglobulin superfamily, with six structurally related members: CNTN1 (F3 or contactin), CNTN2 (TAG-1), CNTN3 (BIG-1), CNTN4 (BIG-2), CNTN5 (NB-2), and CNTN6 (NB-3). They are membrane proteins anchored at the cell surface via a glycosylphosphatidyl inositol (GPI)-link. Their extracellular domains contain six Ig-like domains and four fibronectin type III repeats (fig. 1). Genetic alterations in CNTN3 and CNTN4 genes have been reported in ASD patients. CNTN4 is located at chromosome $3 p$ in the human genome. Deletion of this region causes $3 p$ syndrome, a rare disorder characterized by developmental delay, growth retardation and dysmorphic features. Initially, a child with a characteristic feature of $3 p$ syndrome was diagnosed with ASD and found to carry a de novo translocation disrupting CNTN4 gene [71, 72]. Two additional ASD families associated with CNTN4 gene were later reported. In one family, 2 of the 3 ASD children carried a paternally inherited CNTN4 deletion. In the other family, the child with ASD had a paternally inherited CNTN4 duplication, whereas the father was normal [73]. In a genome-wide CNV study of autistic patients, CNTN4 gene was also found to be more enriched with CNVs among ASD cases as compared with control individuals [3]. Recently, a deletion in CNTN3 gene was identified in an ASD child born from consanguineous parents [74]. Although these reports suggested CNTN3 and CNTN4 as susceptibility genes for ASD, there is no direct correlation between the genetic alteration and ASD in all patients. This may be due to incomplete penetrance or neutral variants of the genes. Indeed, the CNVs in CNTN4 genes are also common in healthy controls [3]. Further studies are necessary to confirm the association of CNTN3 and CNTN4 genes with ASD.

As compared to CNTNs, the association of CNTNAP2 gene (encoding Caspr2) with ASD is more convincing and based on several independent studies. CNTNAP2 is a neurexin family member that binds to CNTNs in cis and transduces the signal inside the cells (fig. 2). CNTNAP2 is highly expressed in the anterior 
part of the developing human cerebral cortex, a region involved in the development of joint attention and language [75]. CNTNAP2 mutations were first identified in Amish individuals with recessive cortical dysplasia-focal epilepsy syndrome and language regression. Two thirds of the affected individuals also fulfill the criteria for ASD. Interestingly, the carboxyl-terminal truncation of CNTNAP2 is associated with severe autism with seizures, language regression and low IQ among these patients [76]. Two independent groups also reported the association of CNTNAP2 with ASD based on genomewide linkage and family-based association mapping [75, 77]. Bakkaloglu et al. [78] sequenced CNTNAP2 gene in 635 ASD and 942 control individuals. They identified thirteen mutations that are rare but unique to the patients, among which eight are deletion mutations. Mutation I869T was present in 4 patients from 3 different families but was not present in any control individuals. Recently, microdeletion and missense mutations in CNTNAP5 have also been identified in some ASD patients, suggesting that other CNTNAPs may also be risk genes for ASD [79].

The role of CNTN and CNTNAP proteins in neural development and function has been studied extensively in cultured neurons and animal models. Similar to other CNTNs, CNTN4 protein has a neurite outgrowth-promoting effect on cultured neurons. It functions as an axon guidance molecule in the mouse olfactory system in vivo [80]. CNTN1/F3 plays an important role in oligodendrocyte differentiation, an important step in the formation of myelin in the central nervous system [81]. CNTN6/NB-3 regulates oriented growth of apical dendrites of deep layer cortical pyramidal neurons [82]. It also plays a role in the formation of vGluR-positive synapses in the cerebellum [83]. CNTNAP2 (Caspr2) is expressed in specific short-segmented pairs along myelinated axons in mice. A closer examination reveals its confined localization to the juxtaparanodal regions and colocalization with Shaker-like potassium channels. Deletion of CNTNAP2 results in elimination of potassium channel clustering at the juxtaparanodal region and subsequent alteration of neurotransmission velocity along the myelinated axons [84]. Interestingly, in an MRI study of white and grey matter morphology of human brains, individuals homozygous for a risk allele of CNTNAP2 (rs7794745) showed significant reductions in white and grey matter volume and abnormality in brain regions implicated in ASD, including occipital and frontal cortices, fusiform gyrus and the cerebellum [85]. Another functional neuroimaging study carried out by Scott-Van
Zeeland et al. [86] also revealed a relationship between frontal lobar connectivity and common genetic variants in CNTNAP2, suggesting that genetic variation in CNTNAP2 predisposes to ASD probably through modulation of frontal lobe connectivity.

Thus, CNTN and CNTNAP proteins play functional roles in various steps of neural circuit formation, including axon guidance, dendrite patterning, synaptic formation and axon myelination. The association of ASD with the human CNTN3, CNTN4 and CNTNAP2 genes provides new insights into the possible pathogenic mechanisms of ASD. In addition to abnormal synapses, patients carrying mutations in CNTN or CNTNAP genes might have subtle to severe alterations in axon targeting, dendrite morphology or neurotransmission velocity, which could also lead to malformation of synapses and malfunction of brain regions involved in ASD.

\section{Conclusions and Perspectives}

The rapid development in technologies for genetic analyses in recent years has significantly advanced our understanding of genetic alterations in ASD. Accumulating evidence suggests that ASD is caused by multiple rare genetic variations rather than limited genetic defects in a few major or common 'autism genes'. Genes encoding CAMs play crucial roles in modulating or fine-tuning synaptic formation and synaptic specification. The findings of ASD-associated genetic alterations in NRXNNLGN-SHANK, integrin-SERT and CNTN-CNTNAP pathways may represent only the tip of an iceberg. More CAMs are emerging as candidate susceptibility genes for ASD. Recently, Wang et al. [4] identified six SNPs on 5 p14.1 that show strong association with ASD. These SNPs fall between two cadherin genes (CDH10 and $\mathrm{CDH} 9$ ), implicating their involvement in ASD. Interestingly, a combination of cadherin/neurexin genes show even more significant association with ASD, suggesting a collective effect of CAMs in the etiology of this disease [4]. Genes encoding ROBO1-4, receptors for the axon guidance molecule slit, are associated with ASD [87]. ROBO regulates SERT expression in Drosophila [87]. Moreover, $\mathrm{ROBO} 3$ is required for hindbrain axon midline crossing, and mutations in the $\mathrm{ROBO} 3$ gene were identified in patients with horizontal gaze palsy with progressive scoliosis [88]. It would be interesting to examine whether developmental deficits caused by $R O B O$ gene mutations would lead to ASD. 
Although genetic changes in many CAM genes have been identified among ASD patients, further studies are necessary to pin point causal mutations or events, and many questions still remain to be addressed about the role of CAMs in ASD. How do these CAMs interact with other crucial players in neural development, including those involved in regulating neuronal migration, axon guidance and synaptogenesis (for example, components of Slit-ROBO, netrin-DCC, netrin-DSCAM pathways)? How are these CAMs regulated by transcriptional and post-transcriptional mechanisms to ensure their spatially and temporally controlled expression and precise subcellular localization for the establishment of normal neural circuits? What mechanisms regulate cross-communication of pathways mediated by distinct classes of CAMs and their interaction partners? How does disruption in the complex networks of interactions among synaptic CAMs and their partners lead to abnormal formation/ function of neural circuits and contribute to the pathogenesis of ASD? Much work is required to address these important questions. In-depth studies of different CAM genes at molecular, cellular and functional levels together with systematic genetic analyses of CAM genes should provide new insights into the pathogenesis of ASD and uncover new players associated with this disease. This may also help in developing biomarkers as well as therapeutic tools for this group of common disorders.

\section{Acknowledgements}

$\mathrm{H}$. Ye and J. Liu are supported by the Ministry of Science and Technology grants 2009CB825402, 2010 CB529603 and National Science Foundation grant 30900845 in China. We apologize to colleagues whose original work cannot be included because of the space limit.

\section{References}

$\checkmark 1$ Lord C, Cook EH, Leventhal BL, Amaral DG: Autism spectrum disorders. Neuron 2000;28:355-363

$\checkmark 2$ Abrahams BS, Geschwind DH: Advances in autism genetics: on the threshold of a new neurobiology. Nat Rev Genet 2008;9:341355.

3 Glessner JT, Wang K, Cai G, Korvatska O, et al: Autism genome-wide copy number variation reveals ubiquitin and neuronal genes. Nature 2009;459:569-573.

4 Wang K, Zhang H, Ma D, Bucan M, et al: Common genetic variants on 5 p14.1 associate with autism spectrum disorders. Nature 2009;459:528-533.

5 Huttenlocher PR, Dabholkar AS: Regional differences in synaptogenesis in human cerebral cortex. J Comp Neurol 1997;387:167178.

66 Walsh CA, Morrow EM, Rubenstein JL: Autism and brain development. Cell 2008;135: 396-400

7 Dalva MB, McClelland AC, Kayser MS: Cell adhesion molecules: signalling functions at the synapse. Nat Rev Neurosci 2007;8:206220.

$>8$ Betancur C, Sakurai T, Buxbaum JD: The emerging role of synaptic cell-adhesion pathways in the pathogenesis of autism spectrum disorders. Trends Neurosci 2009;32: 402-412.

9 Bourgeron T: Cell Adhesion molecules in synaptopathies; in Hortsch $\mathrm{M}$ and Umemori H (ed): The Sticky Synapse. New York, Springer, 2009, pp 141-158.
10 Graf ER, Zhang X, Jin SX, Linhoff MW, et al: Neurexins induce differentiation of GABA and glutamate postsynaptic specializations via neuroligins. Cell 2004;119:1013-1026.

11 Scheiffele P, Fan J, Choih J, Fetter R, et al: Neuroligin expressed in nonneuronal cells triggers presynaptic development in contacting axons. Cell 2000;101:657-669.

12 Dean C, Scholl FG, Choih J, DeMaria S, et al: Neurexin mediates the assembly of presynaptic terminals. Nat Neurosci 2003;6:708716.

13 Tabuchi K, Sudhof TC: Structure and evolution of neurexin genes: insight into the mechanism of alternative splicing. Genomics 2002;79:849-859.

14 Friedman JM, Baross A, Delaney AD, Ally A, et al: Oligonucleotide microarray analysis of genomic imbalance in children with mental retardation. Am J Hum Genet 2006;79:500513.

-15 Zahir FR, Baross A, Delaney AD, Eydoux P et al: A patient with vertebral, cognitive and behavioural abnormalities and a de novo deletion of NRXN1 $\alpha$. J Med Genet 2008;45: 239-243.

16 Feng J, Schroer R, Yan J, Song W, et al: High frequency of neurexin $1 \beta$ signal peptide structural variants in patients with autism. Neurosci Lett 2006;409:10-13.

-17 Bucan M, Abrahams BS, Wang K, Glessner JT, et al: Genome-wide analyses of exonic copy number variants in a family-based study point to novel autism susceptibility genes. PLoS Genet 2009;5:e1000536.
18 Szatmari P, Paterson AD, Zwaigenbaum L, Roberts W, et al: Mapping autism risk loci using genetic linkage and chromosomal rearrangements. Nat Genet 2007;39:319-328.

19 Kim HG, Kishikawa S, Higgins AW, Seong IS, et al: Disruption of neurexin 1 associated with autism spectrum disorder. Am J Hum Genet 2008;82:199-207.

20 Wisniowiecka-Kowalnik B, Nesteruk M, Peters SU, Xia Z, et al: Intragenic rearrangements in NRXN1 in three families with autism spectrum disorder, developmental delay, and speech delay. Am J Med Genet B Neuropsychiatr Genet 2010;153B:983-993.

-21 Zweier C, de Jong EK, Zweier M, Orrico A, et al: CNTNAP2 and NRXN1 are mutated in autosomal-recessive Pitt-Hopkins-like mental retardation and determine the level of a common synaptic protein in Drosophila. Am J Hum Genet 2009;85:655-666.

22 Etherton MR, Blaiss CA, Powell CM, and Sudhof TC: Mouse neurexin-1 $\alpha$ deletion causes correlated electrophysiological and behavioral changes consistent with cognitive impairments. Proc Natl Acad Sci USA 2009; 106:17998-18003.

23 Kirov G, Rujescu D, Ingason A, Collier DA, et al: Neurexin 1 (NRXN1) deletions in schizophrenia. Schizophr Bull 2009;35:851-854.

$>24$ Rujescu D, Ingason A, Cichon S, Pietilainen $\mathrm{OP}$, et al: Disruption of the neurexin 1 gene is associated with schizophrenia. Hum Mol Genet 2009;18:988-996. 
-25 Jamain S, Quach H, Betancur C, Rastam M, et al: Mutations of the X-linked genes encoding neuroligins NLGN3 and NLGN4 are associated with autism. Nat Genet 2003;34:27-29.

-26 Chocholska S, Rossier E, Barbi G, KehrerSawatzki H: Molecular cytogenetic analysis of a familial interstitial deletion Xp22.2-22.3 with a highly variable phenotype in female carriers. Am J Med Genet A 2006;140:604610.

-27 Daoud H, Bonnet-Brilhault F, Vedrine S, Demattei MV, et al: Autism and nonsyndromic mental retardation associated with a de novo mutation in the NLGN4X gene promoter causing an increased expression level. Biol Psychiatry 2009;66:906-910.

-28 Kent L, Emerton J, Bhadravathi V, Weisblatt $\mathrm{E}$, et al: X-linked ichthyosis (steroid sulfatase deficiency) is associated with increased risk of attention deficit hyperactivity disorder, autism and social communication deficits. J Med Genet 2008;45:519-524.

-29 Laumonnier F, Bonnet-Brilhault F, Gomot $\mathrm{M}$, Blanc $\mathrm{R}$, et al: X-linked mental retardation and autism are associated with a mutation in the NLGN4 gene, a member of the neuroligin family. Am J Hum Genet 2004;74: 552-557.

-30 Lawson-Yuen A, Saldivar JS, Sommer S, Picker J: Familial deletion within NLGN4 associated with autism and Tourette syndrome. Eur J Hum Genet 2008;16:614-618.

-31 Macarov M, Zeigler M, Newman JP, Strich D, et al: Deletions of VCX-A and NLGN4: a variable phenotype including normal intellect. J Intellect Disabil Res 2007;51:329-333.

-32 Yan J, Oliveira G, Coutinho A, Yang C, et al: Analysis of the neuroligin 3 and 4 genes in autism and other neuropsychiatric patients. Mol Psychiatry 2005;10:329-332.

$\checkmark 33$ Comoletti D, De Jaco A, Jennings LL, Flynn RE, et al: The Arg451Cys-neuroligin-3 mutation associated with autism reveals a defect in protein processing. J Neurosci 2004;24: 4889-4893.

-34 Zhang C, Milunsky JM, Newton S, Ko J, et al: A neuroligin-4 missense mutation associated with autism impairs neuroligin-4 folding and endoplasmic reticulum export. J Neurosci 2009;29:10843-10854.

-35 Jamain S, Radyushkin K, Hammerschmidt K, Granon S, et al: Reduced social interaction and ultrasonic communication in a mouse model of monogenic heritable autism. Proc Natl Acad Sci USA 2008;105:1710-1715.

-36 Radyushkin K, Hammerschmidt K, Boretius S, Varoqueaux F, et al: Neuroligin-3-deficient mice: model of a monogenic heritable form of autism with an olfactory deficit. Genes Brain Behav 2009;8:416-425.

-37 Tabuchi K, Blundell J, Etherton MR, Hammer RE, et al: A neuroligin-3 mutation implicated in autism increases inhibitory synaptic transmission in mice. Science 2007;318: $71-76$
38 Blundell J, Blaiss CA, Etherton MR, Espinosa F, et al: Neuroligin-1 deletion results in impaired spatial memory and increased repetitive behavior. J Neurosci 2010;30:21152129.

39 Boeckers TM, Bockmann J, Kreutz MR, Gundelfinger ED: ProSAP/Shank proteins a family of higher order organizing molecules of the postsynaptic density with an emerging role in human neurological disease. J Neurochem 2002;81:903-910.

40 Durand CM, Betancur C, Boeckers TM, Bockmann J, et al: Mutations in the gene encoding the synaptic scaffolding protein SHANK3 are associated with autism spec trum disorders. Nat Genet 2007;39:25-27.

41 Jeffries AR, Curran S, Elmslie F, Sharma A et al: Molecular and phenotypic characterization of ring chromosome 22. Am J Med Genet A 2005; 137:139-147.

42 Manning MA, Cassidy SB, Clericuzio C, Cherry AM, et al: Terminal 22q deletion syndrome: a newly recognized cause of speech and language disability in the autism spectrum. Pediatrics 2004; 114:451-457.

43 Moessner R, Marshall CR, Sutcliffe JS, Skaug J, et al: Contribution of SHANK3 mutations to autism spectrum disorder. Am J Hum Genet 2007;81:1289-1297.

44 Gauthier J, Spiegelman D, Piton A, Lafreniere RG, et al: Novel de novo SHANK3 mutation in autistic patients. Am J Med Genet B Neuropsychiatr Genet 2009;150B:421-424.

45 Qin J, Jia M, Wang L, Lu T, et al: Association study of SHANK3 gene polymorphisms with autism in Chinese Han population. BMC Med Genet 2009; 10:61.

46 Sykes NH, Toma C, Wilson N, Volpi EV, et al: Copy number variation and association analysis of SHANK3 as a candidate gene for autism in the IMGSAC collection. Eur J Hum Genet 2009;17:1347-1353.

47 Chubykin AA, Atasoy D, Etherton MR, Brose N, et al: Activity-dependent validation of excitatory versus inhibitory synapses by neuroligin-1 versus neuroligin-2. Neuron 2007;54:919-931.

$48 \mathrm{Xu}$ J, Xiao N, Xia J: Thrombospondin 1 accelerates synaptogenesis in hippocampal neurons through neuroligin 1 . Nat Neurosci 2010;13:22-24.

49 Sala C, Piech V, Wilson NR, Passafaro M, et al: Regulation of dendritic spine morphology and synaptic function by Shank and Homer. Neuron 2001;31:115-130.

50 Roussignol G, Ango F, Romorini S, Tu JC, et al: Shank expression is sufficient to induce functional dendritic spine synapses in aspiny neurons. J Neurosci 2005;25:3560-3570.

51 Weiss LA, Veenstra-Vanderweele J, Newman DL, Kim SJ, et al: Genome-wide association study identifies ITGB3 as a QTL for whole blood serotonin. Eur J Hum Genet 2004;12 949-954.

52 Cook EH, Leventhal BL: The serotonin system in autism. Curr Opin Pediatr 1996;8 348-354.
53 Schain RJ, Freedman DX: Studies on 5-hydroxyindole metabolism in autistic and other mentally retarded children. J Pediatr 1961; 58:315-320.

54 Weiss LA, Kosova G, Delahanty RJ, Jiang L, et al: Variation in ITGB3 is associated with whole-blood serotonin level and autism susceptibility. Eur J Hum Genet 2006;14:923931.

55 Coutinho AM, Sousa I, Martins M, Correia C, et al: Evidence for epistasis between SLC6A4 and ITGB3 in autism etiology and in the determination of platelet serotonin levels. Hum Genet 2007;121:243-256.

$\checkmark 56$ Ma DQ, Rabionet R, Konidari I, Jaworski J, et al: Association and gene-gene interaction of SLC6A4 and ITGB3 in autism. Am J Med Genet B Neuropsychiatr Genet 2010; 153B:477-483.

57 Mei H, Cuccaro ML, Martin ER: Multifactor dimensionality reduction-phenomics: a novel method to capture genetic heterogeneity with use of phenotypic variables. Am J Hum Genet 2007;81:1251-1261.

58 Weiss LA, Ober C, Cook EH Jr: ITGB3 shows genetic and expression interaction with SLC6A4. Hum Genet 2006;120:93-100.

59 Cook EH Jr, Courchesne R, Lord C, Cox NJ, et al: Evidence of linkage between the serotonin transporter and autistic disorder. Mol Psychiatry 1997;2:247-250.

60 Consortium IMGSoA: A genomewide screen for autism: strong evidence for linkage to chromosomes 2q, 7q, and 16p. Am J Hum Genet 2001;69:570-581.

-61 Yonan AL, Alarcon M, Cheng R, Magnusson PK, et al: A genomewide screen of 345 families for autism-susceptibility loci. Am J Hum Genet 2003;73:886-897.

62 Brune CW, Kim SJ, Salt J, Leventhal BL, et al: 5-HTTLPR genotype-specific phenotype in children and adolescents with autism. Am J Psychiatry 2006;163:2148-2156.

63 McCauley JL, Olson LM, Dowd M, Amin T, et al: Linkage and association analysis at the serotonin transporter (SLC6A4) locus in a rigid-compulsive subset of autism. Am J Med Genet B Neuropsychiatr Genet 2004; 127B:104-112.

64 Sutcliffe JS, Delahanty RJ, Prasad HC, McCauley JL, et al: Allelic heterogeneity at the serotonin transporter locus (SLC6A4) confers susceptibility to autism and rigid-compulsive behaviors. Am J Hum Genet 2005;77: 265-279.

65 Veenstra-Vanderweele J, Jessen TN, Thompson BJ, Carter M, et al: Modeling rare gene variation to gain insight into the oldest biomarker in autism: construction of the serotonin transporter Gly56Ala knock-in mouse. J Neurodev Disord 2009;1:158-171.

66 Carneiro AM, Cook EH, Murphy DL, Blakely RD: Interactions between integrin $\alpha \operatorname{IIb} \beta 3$ and the serotonin transporter regulate serotonin transport and platelet aggregation in mice and humans. J Clin Invest 2008;118: 1544-1552. 
67 Condic ML, Letourneau PC: Ligand-induced changes in integrin expression regulate neuronal adhesion and neurite outgrowth. Nature 1997;389:852-856.

68 Chavis P, Westbrook G: Integrins mediate functional pre-and postsynaptic maturation at a hippocampal synapse. Nature 2001;411: 317-321.

69 Hutcheson HB, Olson LM, Bradford Y, Folstein SE, et al: Examination of NRCAM, LRRN3, KIAA0716, and LAMB1 as autism candidate genes. BMC Med Genet 2004;5:12.

-70 Correia C, Coutinho AM, Almeida J, Lontro $\mathrm{R}$, et al: Association of the $\alpha 4$ integrin subunit gene (ITGA4) with autism. Am J Med Genet B Neuropsychiatr Genet 2009; 150B:1147-1151.

71 Fernandez T, Morgan T, Davis N, Klin A, et al: Disruption of contactin 4 (CNTN4) results in developmental delay and other features of $3 \mathrm{p}$ deletion syndrome. Am J Hum Genet 2004;74:1286-1293.

-72 Fernandez T, Morgan T, Davis N, Klin A, et al: Disruption of contactin 4 (CNTN4) results in developmental delay and other features of $3 p$ deletion syndrome. Am J Hum Genet 2008;82:1385.

73 Roohi J, Montagna C, Tegay DH, Palmer LE, et al: Disruption of contactin 4 in three subjects with autism spectrum disorder. J Med Genet 2009;46:176-182.

74 Morrow EM, Yoo SY, Flavell SW, Kim TK, et al: Identifying autism loci and genes by tracing recent shared ancestry. Science 2008;321: 218-223.
75 Alarcon M, Abrahams BS, Stone JL, Duvall JA, et al: Linkage, association, and gene-expression analyses identify CNTNAP2 as an autism-susceptibility gene. Am J Hum Genet 2008;82:150-159.

76 Strauss KA, Puffenberger EG, Huentelman MJ, Gottlieb S, et al: Recessive symptomatic focal epilepsy and mutant contactin-associated protein-like 2. N Engl J Med 2006;354: 1370-1377.

77 Arking DE, Cutler DJ, Brune CW, Teslovich TM, et al: A common genetic variant in the neurexin superfamily member CNTNAP2 increases familial risk of autism. Am J Hum Genet 2008;82:160-164.

78 Bakkaloglu B, O’Roak BJ, Louvi A, Gupta AR, et al: Molecular cytogenetic analysis and resequencing of contactin associated protein-like 2 in autism spectrum disorders. Am J Hum Genet 2008;82:165-173.

79 Pagnamenta AT, Bacchelli E, de Jonge MV, Mirza G, et al: Characterization of a family with rare deletions in CNTNAP5 and DOCK4 suggests novel risk loci for autism and dyslexia. Biol Psychiatry 2010;68:320-328.

80 Kaneko-Goto T, Yoshihara S, Miyazaki H, Yoshihara Y: BIG-2 mediates olfactory axon convergence to target glomeruli. Neuron 2008;57:834-846.

$81 \mathrm{Hu}$ QD, Ang BT, Karsak M, Hu WP, et al: F3/ contactin acts as a functional ligand for Notch during oligodendrocyte maturation. Cell 2003;115:163-175.
82 Ye H, Tan YL, Ponniah S, Takeda Y, et al: Neural recognition molecules CHL1 and NB-3 regulate apical dendrite orientation in the neocortex via PTP $\alpha$. EMBO J 2008;27: 188-200.

-83 Sakurai K, Toyoshima M, Ueda H, Matsubara K, et al: Contribution of the neural cell recognition molecule NB-3 to synapse formation between parallel fibers and Purkinje cells in mouse. Dev Neurobiol 2009;69:811824.

84 Poliak S, Salomon D, Elhanany H, Sabanay $\mathrm{H}$, et al: Juxtaparanodal clustering of Shakerlike $\mathrm{K}^{+}$channels in myelinated axons depends on Caspr2 and TAG-1. J Cell Biol 2003; 162:1149-1160.

85 Tan GC, Doke TF, Ashburner J, Wood NW, et al: Normal variation in fronto-occipital circuitry and cerebellar structure with an autism-associated polymorphism of CNTNAP2. Neuroimage 2010;53:1030-1042.

86 Scott-Van Zeeland AA, Abrahams BS, Alvarez-Retuerto AI, Sonnenblick LI, et al: Altered functional connectivity in frontal lobe circuits is associated with variation in the autism risk gene CNTNAP2. Sci Transl Med 2010;2:56ra80.

87 Anitha A, Nakamura K, Yamada K, Suda S, et al: Genetic analyses of roundabout (ROBO) axon guidance receptors in autism. Am J Med Genet B Neuropsychiatr Genet 2008; 147B:1019-1027.

$>88$ Jen JC, Chan WM, Bosley TM, Wan J, et al: Mutations in a human $R O B O$ gene disrupt hindbrain axon pathway crossing and morphogenesis. Science 2004;304:1509-1513. 